\title{
The Effects of Terrorism on Trade: A Factor Supply Approach
}

\author{
Subhayu Bandyopadhyay and Todd Sandler
}

The conventional view of terrorism is that it raises risks and, as a result, reduces trade. The authors use a factor supply approach to show that this hypothesis is not necessarily correct. They use a twogood, two-factor, small open economy model to show that terrorism can either reduce or raise trade depending on critical factors, such as the impact of terrorism on the intensive factor of the export or the import sector. They then extend the analysis to models with several goods and factors and identify conditions under which trade may rise or fall with a greater incidence of terrorism. Finally, they provide an analysis of the effects of terrorism on trade in the presence of an optimal counterterrorism policy. The authors find that a nation's adjustment of its counterterrorism level in response to a greater terrorist threat may moderate the impact of terrorism on trade. (JEL F11, F52, H56)

Federal Reserve Bank of St. Louis Review, Third Quarter 2014, 96(2), pp. 229-41.

$\mathbf{T}$ his article reconsiders the effects of terrorism on trade. The conventional wisdom is that trade with a nation affected by terrorism involves higher risks. The consequent rise in the transaction costs is akin to a rise in transportation costs, which tend to reduce trade. Based on such an argument, Nitsch and Schumacher (2004) and Blomberg and Hess (2006) find evidence that terrorism indeed tends to depress a nation's trade. However, terrorism not only affects transaction costs for a trading nation, but also can deplete a nation's supply of scarce productive factors. This depletion may result from terrorist groups drawing the nation's radicalized elements into terrorism activities or terrorist groups directing attacks on the nation's people or productive capital.

Negative impacts on the economy may also stem from foreign investors being dissuaded from investing because of potential terrorist activities. The literature in this area has already documented these effects, ${ }^{1}$ but there has been no analysis of how these factor supply effects may influence the pattern of trade. This is an important gap because once factor supply effects are considered, the predictions of how terrorism may affect trade may be reversed. ${ }^{2}$ When terrorism affects a nation's factor supplies, its production possibility frontier will shift and

\footnotetext{
Subhayu Bandyopadhyay is a research officer and economist at the Federal Reserve Bank of St. Louis. Todd Sandler is the Vibhooti Shukla Professor of Economics and Political Economy and director of the Center for Global Collective Action at the University of Texas at Dallas. The authors thank Maria Canon and YiLi Chien for their helpful comments and Lowell Ricketts for research assistance.

(c) 2014, The Federal Reserve Bank of St. Louis. The views expressed in this article are those of the author(s) and do not necessarily reflect the views of the Federal Reserve System, the Board of Governors, or the regional Federal Reserve Banks. Articles may be reprinted, reproduced, published, distributed, displayed, and transmitted in their entirety if copyright notice, author name(s), and full citation are included. Abstracts, synopses, and other derivative works may be made only with prior written permission of the Federal Reserve Bank of St. Louis.
} 


\section{Bandyopadhyay and Sandler}

may twist. In a multifactor, multigood world, as in the standard Heckscher-Ohlin model, depletion of some factors may shift the production possibility frontier in the direction of increasing the exportable commodity. In this case, trade tends to rise with an increased level of terrorism, moderating and opposing the trade-reducing effects of the increased terrorism-related transaction costs noted in the literature. In contrasting situations, the factor supply effects may reduce the supply of the exportable good. In such cases, trade is reduced and the factor supply effects compound the trade-reducing effects of increased transaction costs. ${ }^{3}$ Thus, a priori, it is not possible to predict whether terrorism will raise or reduce trade. The objective of this article is to identify conditions under which a greater incidence of terrorism is likely to raise or reduce a nation's trade. ${ }^{4}$

Although we find that terrorism may raise trade, the loss of a nation's productive resources is necessarily welfare reducing for a small open economy. Therefore, regardless of the effect on trade, the terrorists do impose costs (and achieve their goals) by inflicting damage on their target nation. This conclusion, however, does not extend to a large open economy. The trade literature has established that while a rise in a factor endowment must benefit a small open economy, it may hurt a large nation because of terms-of-trade effects. Similarly, if terrorism improves a nation's terms of trade by reducing the supply of the exportable good, the negative welfare consequences of terrorism may be mitigated and, in extreme cases, reversed. Our analysis helps to shed light on these issues, and further analysis with endogenous terms of trade will help to provide a more complete picture. This avenue of research will show under which circumstances terrorists are able to hurt an economy through the trade channel. Many terrorist groups state that one of their explicit goals is to hurt the economies of target countries (Enders and Sandler, 2012).

In this article, we present a small, open economy model of trade in which terrorism affects factor supplies. We establish necessary and/or sufficient conditions for terrorism to raise/ reduce trade and evaluate these conditions within the context of standard neoclassical trade models. The following section presents the analysis for a two-good, two-factor small open economy. We then extend the analysis to the case of several goods and several factors. A separate section presents the analysis in the presence of an optimal counterterrorism policy.

\section{A 2 × 2 SMALL OPEN ECONOMY MODEL}

Consider a small open economy that suffers from terrorism. Competitive firms in this nation produce two goods, goods 1 and 2, with two factors of production, labor and capital. Factor endowments are subject to depletion caused by the terrorism and are given by ${ }^{5}$

$$
L(T), L^{\prime}(T) \leq 0 ; \text { and } K(T), K^{\prime}(T) \leq 0
$$

where $T$ is an index of terrorism and $L$ and $K$ are the endowments of labor and capital, respectively, available for production. Terrorism depletes these factors by pulling them into the terrorism sector or by inflicting damage by means of attack. Terrorism-associated risk can also reduce investment and, hence, capital formation (Blomberg, Hess, and Orphanides, 2004, 
Gaibulloev and Sandler, 2008, 2011). Terrorism risks can also increase the cost of conducting business, thereby affecting labor and capital. Given that the nation is a small open economy, the prices of goods 1 and 2 ( $p_{1}$ and $p_{2}$, respectively) are exogenously given.

Following Dixit and Norman (1980), we consider a representative consumer who derives utility, $u$, from consumption. The trade balance for this economy requires the representative consumer's expenditure on consumption to be equal to the nation's revenues from the production of the two goods. The consumer's expenditure is represented by a standard expenditure function, $e\left(p_{1}, p_{2}, u\right)$, and the nation's revenues are denoted by a standard revenue function, $R\left(p_{1}, p_{2}, L, K\right) .{ }^{6}$ Choosing good 2 as the numeraire, we set its price, $p_{2}$, at unity. Using equation (1), we can write the trade balance relationship as

$$
e\left(p_{1}, 1, u\right)=R\left[p_{1}, 1, L(T), K(T)\right]
$$

where the country's expenditure matches its revenue. By the implicit function theorem, equation (2) yields

$$
u=u\left(p_{1}, T\right) \text {, where } \frac{\partial u}{\partial T}=u_{T}(\bullet)=\frac{R_{L} L^{\prime}(T)+R_{K} K^{\prime}(T)}{e_{u}} .
$$

The term $u_{T}(\bullet)$ measures the loss in utility for the representative consumer from a marginal rise in terrorism. The last expression in equation (3) may be explained as follows: The terms $R_{L} L^{\prime}(T)$ and $R_{K} K^{\prime}(T)$ reflect the revenue losses from the damaging effect of terrorism on the labor and capital endowments, respectively. The Mathematical Appendix shows that the inverse of $e_{u}$ measures the marginal utility of income. Thus, the last term in equation (3) is the utility equivalent of revenue losses from a greater incidence of terrorism.

The partial derivative of the expenditure function with respect to the price of good $i$ yields the domestic demand function for the good. Moreover, the domestic production of good $i$ is given by the corresponding partial derivative of the revenue function (see note 6). Net export of good $i$, say, $E X^{i}$, is the difference between the nation's domestic production and its domestic demand. Using equations (1) through (3), we have

$$
E X^{i}=R_{i}\left[p_{1}, 1, L(T), K(T)\right]-e_{i}\left[p_{1}, 1, u\left(p_{1}, T\right)\right]=E X^{i}(T),
$$

where the last term on the right-hand side of equation (4) suppresses prices from the functional form. Equation (4) can be used to find the comparative static effect of terrorism on trade. In a two-good world with given prices, the volume of trade is proportional to the volume of net export of either good. ${ }^{7}$ Therefore, we can focus only on good 1. Differentiating equation (4) yields

$$
\frac{\partial E X^{1}}{\partial T}=R_{1 L} L^{\prime}(T)+R_{1 K} K^{\prime}(T)-e_{1 u} u_{T}
$$




\section{Bandyopadhyay and Sandler}

Note that $R_{1 v}\left(=\frac{\partial R_{1}}{\partial v}=\frac{\partial X^{1}}{\partial v}\right)$ represents the increase (or decrease) in production of good 1 (say, $X^{1}$ ) in response to an increase in factor endowment $v$. Therefore, the first two terms on the right-hand side of equation (5) reflect the changes in production of good 1 from terrorisminduced destruction of labor and capital endowments, respectively. The last term indicates the fall in demand for good 1 caused by the terrorism-related utility loss of the representative consumer. The net effect of these supply and demand changes on the export of good 1 is reflected in equation (5).

Now, we use equation (3) to substitute for $u_{T}$ in equation (5). In addition, in view of note 6 , we can substitute $w$ (wage rate for labor) and $r$ (rental rate for capital) for $R_{L}$ and $R_{K}$, respectively. These substitutions and some rearrangement of terms yield ${ }^{8}$

$$
\frac{\partial E X^{1}}{\partial T}=\left(R_{1 L}-w \times m p c^{1}\right) L^{\prime}(T)+\left(R_{1 K}-r \times m p c^{1}\right) K^{\prime}(T) .
$$

Without loss of generality, consider good 1 to be the export good (i.e., $E X^{1}>0$ ). Using equation (6) and note 7, we conclude that trade will rise with terrorism (i.e., $\frac{\partial E X^{1}}{\partial T}>0$ ) if and only if

$$
R_{1 L}-w \times m p c^{1}<-z(T)\left(R_{1 K}-r \times m p c^{1}\right), z(T) \equiv \frac{K^{\prime}(T)}{L^{\prime}(T)}>0,
$$

where $z$ represents the relative rate of terrorism-induced destruction of capital and labor. The intuition behind equation (7) is best understood by using the special cases below.

For simplicity, we first consider a case where only labor is depleted by terrorism, but the capital stock is unaffected. ${ }^{9}$ In this case, $K^{\prime}(T)=0 \Rightarrow z(T)=0$, and hence equation (7) can be reduced to

$$
\frac{\partial E X^{1}}{\partial T}>0 \text { if and only if } R_{1 L}<w \times m p c^{1} .
$$

Now let us consider the special case of the Heckscher-Ohlin model: Here, in addition to perfect competition, we invoke constant returns to scale in production. If good 1 is capital intensive, the output of good 1 is necessarily negatively related to the abundance of labor (i.e., $R_{1 L}<0$ ) from the Rybczynski theorem. In this case, normality in the consumption of good 1 (i.e., $m p c^{1}>0$ ) is sufficient to ensure that equation (8) is satisfied, so that terrorism must raise trade. The following intuition applies. Terrorism reduces labor endowment, leading to an increase in the production of good 1. Also, the reduction of the labor endowment leads to a loss in labor income for the representative consumer, which translates to a fall in demand for good 1, assuming normality. Thus, the export of good 1 must increase because of a rise in its production and a fall in its domestic demand. This finding contrasts with the trade effects of terrorism identified in the literature by Nitsch and Schumacher (2004) and Blomberg and Hess (2006). The difference stems from the fact that our representation highlights the effect of terrorism on 
factor supplies rather than transaction costs. It is important to note, however, that even though terrorism expands trade in the example above, trade may shrink in other scenarios. The analysis below identifies and discusses these alternative possibilities.

\section{A MULTIGOOD, MULTIFACTOR $n \times m$ MODEL}

The analysis is now extended to a small open economy that trades $n$ goods and uses $m$ factors of production. The price vector for the $n$ goods is given by $p=\left(p_{1}, p_{2}, \ldots, p_{n}\right)$, while the endowment vector of the $m$ factors is denoted by $v=\left(v^{1}, v^{2}, \ldots, v^{m}\right)$. As in the earlier section, factor endowments are again subject to terrorism-induced depletion, such that

$$
v(T)=\left[v^{1}(T), v^{2}(T), \ldots v^{m}(T)\right], \frac{\partial v^{j}(T)}{\partial T}=v_{T}^{j} \leq 0 .
$$

Again, terrorism destroys resources, attracts some resources into the terrorism sector, raises risks, and increases the cost of conducting business. The trade balance for this multigood, multifactor open economy requires expenditure to match revenue:

$$
e(p, u)=R[p, v(T)]
$$

Based on the implicit function theorem, equation (10) yields

$$
u=u(p, T), \frac{\partial u}{\partial T}=u_{T}(\bullet)=\frac{\sum_{j=1}^{m} R_{v^{j}} v^{j^{\prime}}(T)}{e_{u}}=\frac{\sum_{j=1}^{m} \omega^{j} v^{j^{\prime}}(T)}{e_{u}},
$$

where $\omega^{j}=R_{v^{j}}$ is the price of factor $j$. Using equation (11) and suppressing the output price vector in the last term on the right-hand side of the following equation yields

$$
E X^{i}=R_{i}[p, v(T)]-e_{i}[p, u(p, T)]=E X^{i}(T), i=1,2, \ldots, n
$$

where good $i$ is exportable (importable) if $E X^{i}$ is positive (negative). Differentiating equation (12) with respect to terrorism and substituting equation (11) into the resulting expression, we can express the terrorism-induced change in the net export of good $i$ as

$$
\frac{\partial E X^{i}}{\partial T}=\sum_{j=1}^{m}\left(R_{i v^{j}}-m p c^{i} \times \omega^{j}\right) v^{j^{\prime}}(T), i=1,2, \ldots, n .
$$

Equation (13) may be understood using the following logic. For any factor $j, v^{j^{\prime}}(T)$ represents depletion of its endowment as a result of terrorism. The term $R_{i v^{j}}$ is the change in production of good $i$ for a marginal change in the endowment of factor $j$. On the other hand, along the lines of the income effect discussed following equation (8), the term $m p c^{i} \times \omega^{j}$ reflects the fall in demand for good $i$ resulting from the depletion of factor income from destruction of factor $j$. Therefore, the net effect on export of good $i$ from damage to a particular factor $j$ is captured by the term $\left(R_{i v^{j}}-m p c^{i} \times \omega^{j}\right) v^{j^{\prime}}(T)$. Given that terrorism can potentially damage all 


\section{Bandyopadhyay and Sandler}

$m$ factors, the total effect on the export of good $i$ must be reflected by the sum of these terms over all the factors.

Now, consider one of the exportable goods such that $E X^{i}>0$. Given that $v^{j^{\prime}}(T)$ is nonpositive for all factors, a necessary condition for $\frac{\partial E X^{i}}{\partial T}>0$ is that for (at least) one factor $j^{*}$, it must be that

$$
\left(R_{i v^{*}}-m p c^{i} \times \omega^{j^{*}}\right) v^{j^{* \prime}}(T)>0 \Rightarrow v^{j^{* \prime}}(T)<0, \text { and also } R_{i v^{j^{*}}}-m p c^{i} \times \omega^{j^{*}}<0
$$

Equation (8) in the previous section is a special case of equation (14). Although equation (8) is both a necessary and a sufficient condition for trade to rise with terrorism, in the general model considered here, it is simply a necessary condition for the export of a particular good (not necessarily the summed value of all exports) to rise with terrorism. Below, we provide some textbook cases of trade nested within the current $n \times m$ model and evaluate equations (13) and (14), where appropriate, within the contexts of these special cases.

\section{Case 1: A $2 \times 1$ Ricardian Model}

Consider a Ricardian model where there are two goods $(n=2)$ and only one factor of production, denoted by labor (i.e., $m=1$ ). Under standard assumptions, this model yields complete specialization in the production of the exportable good (say, good 1). If good 2 is the numeraire, then balance of trade requires that

$$
p_{1} E X^{1}=I M^{2}, E X^{1}=X^{1}-c^{1} \text {, and } I M^{2}=c^{2},
$$

where $X^{1}$ is the production of good 1 and $c^{i}$ is the domestic consumption of good $i(i=1,2)$. As terrorism reduces the labor endowment ( $\operatorname{since} L^{\prime}(T)<0$ ), the output of good 1 must fall. Consumption of good 1 also falls because of the income effect discussed previously. A rise in exports may appear possible; however, the loss of income will also reduce the consumption of good 2, which denotes imports in this representation. When we use this fact in equation (15), terrorism must reduce trade.

\section{Case 2: A $2 \times 3$ Specific Factors Model}

Here, we consider a standard specific factors model and show that, as in the HeckscherOhlin model, terrorism may raise or reduce trade. We offer two contrasting examples within the context of this model. In the first, terrorism must raise trade; in the second, terrorism must reduce trade. In a specific factors model, this establishes that, unless the pattern of the effects of terrorism on the different factor endowments is known, the effects on trade cannot be predicted.

Assume that two goods $(n=2)$ are produced by three factors: labor, land, and capital $(m=3)$. Think of one of the goods as being food and the other as being manufacturing. Further assume that labor is used to produce both goods, while land and capital are specific factors for food and manufacturing, respectively. Let manufacturing (good 1) be the export good and food (good 2) be the import good. Using equation (13), we have 


$$
\frac{\partial E X^{1}}{\partial T}=\left(R_{1 L}-m p c^{1} \times w\right) L^{\prime}(T)+\left(R_{1 K}-m p c^{1} \times r\right) K^{\prime}(T)+\left(R_{1 \lambda}-m p c^{1} \times \rho\right) \lambda^{\prime}(T),
$$

where $\rho$ and $\lambda(T)$ are the land rental and land endowment, respectively.

Consider the possibility that terrorism reduces land availability for food production but does not affect other factors of production. This may be the case where a guerrilla group that deploys terrorist attacks controls land in the countryside, as in the case of the Revolutionary Armed Forces of Colombia (FARC) or the Shining Path in the 1980s in Peru. In this case, $L^{\prime}(T)=K^{\prime}(T)=0$ and $\lambda^{\prime}(T)<0$, such that equation (16) degenerates to

$$
\frac{\partial E X^{1}}{\partial T}=\left(R_{1 \lambda}-m p c^{1} \times \rho\right) \lambda^{\prime}(T) .
$$

Equation (17) corresponds to equation (14). In this specific factors model, a standard result is that the rise in the land endowment must reduce the output of the manufacturing good, denoted by $X^{1}$ (i.e., $R_{1 \lambda}=\frac{\partial X^{1}}{\partial \lambda}<0$ ). Given $R_{1 \lambda}<0$, equation (17) implies that the normality of good 1 is sufficient for terrorism to augment trade. This follows because, as terrorism destroys land that can be used for cultivation, output of food falls and so some labor is reallocated to manufacturing, where output increases. However, the loss in national income resulting from the decline in productive land must reduce domestic consumption of the manufactured good (under normality). The resulting expansion of the gap between the nation's domestic supply of manufacturing and its domestic demand is absorbed through an expansion of manufacturing export. Thus, in this example, terrorism results in enhanced trade.

Now, we put forward an example where terrorism must reduce trade. Consider a scenario where terrorism destroys capital but does not affect land or labor resources. This would be true of terrorist groups that target infrastructure and foreign direct investment, such as Euskadi ta Askatasuna (ETA) in Spain (Enders and Sandler, 1996). In this case, $L^{\prime}(T)=\lambda^{\prime}(T)=0$ and $K^{\prime}(T)<0$. When applied to good 2, equation (13) gives

$$
\frac{\partial E X^{2}}{\partial T}=\left(R_{2 K}-m p c^{2} \times r\right) K^{\prime}(T)>0
$$

if and only if $R_{2 K}-m p c^{2} \times r<0$.

In this model, a rise in capital must reduce the output of food, denoted by $X^{2}$ (i.e., $\left.R_{2 K}=\frac{\partial X^{2}}{\partial K}<0\right)$. Given $R_{2 K}<0$ and the import nature of good 2 (i.e., $I M^{2}=-E X^{2}>0$ ), equation (18) gives

$$
\frac{\partial E X^{2}}{\partial T}=\left(R_{2 K}-m p c^{2} \times r\right) K^{\prime}(T)>0 \Rightarrow \frac{\partial I M^{2}}{\partial T}=\frac{\partial\left(-E X^{2}\right)}{\partial T}<0 .
$$

In this alternative scenario, terrorism reduces the volume of imports for two reasons. First, the terrorism-induced destruction of productive capital shrinks manufacturing and 


\section{Bandyopadhyay and Sandler}

some manufacturing labor is reallocated to agriculture, so that food production rises. Second, the loss of national income caused by the terrorism-induced capital depletion reduces the domestic demand for food. These two factors shrink the gap between domestic demand and domestic supply of food, thereby reducing the import of food. Since, in this example, capital is the only factor that is reduced by terrorism, trade must decline.

\section{THE 2 × 2 SMALL OPEN ECONOMY MODEL UNDER AN OPTIMAL COUNTERTERRORISM POLICY}

Next, we extend the investigation to analyze the effect of terrorism on trade in the $2 \times 2$ model in the presence of an optimal counterterrorism policy. Such policies take two essential forms: defensive measures intended to deter future terrorist acts through the hardening of potential targets or longer prison sentences for convicted terrorists (Landes, 1978) and proactive measures to limit the terrorists' capabilities by capturing or killing their operatives or leaders (Sandler and Siqueira, 2006) ${ }^{10}$ Drone attacks on al-Qaida's leadership or the infiltration of terrorist groups also denote proactive counterterrorism measures. Suppose that terrorism can be reduced by either form of counterterrorism measures, denoted by $\mu$. These measures are reflected in the terrorism index, $T$, used previously, which now takes the form

$$
T=T(\alpha, \mu), T_{\alpha}>0, \text { and } T_{\mu}<0,{ }^{11}
$$

where $\alpha$ is a shift parameter capturing exogenous factors that augment terrorism for any given level of $\mu$. As in equation (1), labor and capital endowments may be reduced by terrorism. Additionally, we assume that (i) counterterrorism effort is paid for in units of good 2 (i.e., the numeraire) and (ii) counterterrorism's marginal cost is constant at unity. Therefore, the trade balance condition must reflect the equality between consumption expenditure and production revenues, net of the counterterrorism expense. Based on equations (1) and (20) and the modified trade balance, this relationship may be represented as

$$
e\left(p_{1}, 1, u\right)=R\left\{p_{1}, 1, L[T(\alpha, \mu)], K[T(\alpha, \mu)]\right\}-\mu .
$$

Suppressing $p_{1}$ from the functional form and using the implicit function theorem, we can reexpress equation (21) as

$$
\begin{gathered}
u=u(\alpha, \mu), \frac{\partial u}{\partial \alpha}=u_{\alpha}(\bullet)=\frac{\left[R_{L} L^{\prime}(T)+R_{K} K^{\prime}(T)\right] T_{\alpha}}{e_{u}} \text { and } \\
\frac{\partial u}{\partial \mu}=u_{\mu}(\bullet)=\frac{\left[R_{L} L^{\prime}(T)+R_{K} K^{\prime}(T)\right] T_{\mu}-1}{e_{u}} .
\end{gathered}
$$

Now, counterterrorism policy is a choice variable for the government, which seeks to maximize the utility of the representative consumer. While greater counterterrorism effort helps to contain the terrorism threat, and thereby saves resources, it also costs the nation units of potential consumption of good 2 (or potential consumption of good 1, because good 2 can be 
traded for good 1 at constant terms of trade). The balance of these marginal gains and losses determines the optimal level of counterterrorism policy. The first-order condition reflecting this choice is obtained by setting $u_{\mu}(\bullet)$ equal to zero ${ }^{12}$ :

$$
\left\{R_{L}(\bullet) L^{\prime}[T(\bullet)]+R_{K}(\bullet) K^{\prime}[T(\bullet)]\right\} T_{\mu}(\bullet)=1 .
$$

At the margin, as counterterrorism reduces terrorism, labor endowment rises, which in turn allows for additional production revenues of $R_{L} L^{\prime}(T) T_{\mu}$. Similarly, $R_{K} K^{\prime}(T) T_{\mu}$ measures the additional revenues arising from the capital-augmenting effect of counterterrorism effort. The left-hand side of equation (23) measures the sum of these two effects, which denotes the marginal national gain from counterterrorism effort. The right-hand side measures the marginal cost of counterterrorism for the nation, normalized at a value of 1 . Hence, equation (23) implicitly defines the optimal counterterrorism policy as

$$
\mu=\mu(\alpha)
$$

Using equations (20) through (24), we can represent the net export of good 1 as

$$
E X^{1}=R_{1}\left[p_{1}, 1, L\{T[\alpha, \mu(\alpha)]\}, K\{T[\alpha, \mu(\alpha)]\}\right]-e_{1}\left\{p_{1}, 1, u[\alpha, \mu(\alpha)]\right\} .
$$

Suppressing price from the functional form and noting that $u_{\mu}(\bullet)=0$, we differentiate equation (25) and use equation (22) to derive

$$
\frac{\partial E X^{1}}{\partial \alpha}=\left[R_{1 L} L^{\prime}(T)+R_{1 K} K^{\prime}(T)\right] \times\left[T_{\alpha}+T_{\mu} \mu^{\prime}(\alpha)\right]-m p c^{1} \times\left[R_{L} L^{\prime}(T)+R_{K} K^{\prime}(T)\right] T_{\alpha} .
$$

The first term on the right-hand side of equation (26) measures changes in the supply of good 1 resulting from labor and capital losses stemming from a change in terrorism due to both an exogenous rise in $\alpha$ and the endogenous response of $\mu$. Moreover, the last term of equation (26) measures the change in the demand for good 1 resulting from the terrorisminduced loss in utility. Because $u_{\mu}(\bullet)=0$, the effect on demand related to the change in $\mu$ disappears and only the effect of the exogenous change in terrorism (represented by $T_{\alpha}$ ) remains.

Assuming that good 1 is the export good (see the section titled "A $2 \times 2$ Small Open Economy Model"), we consider the case where $K^{\prime}(T)=0$ and $L^{\prime}(T)<0$, such that terrorism affects labor but not capital. Given that $R_{L}=w$, equation (26) yields

$$
\begin{aligned}
& \frac{\partial E X^{1}}{\partial \alpha}=L^{\prime}(T)\left[\left(R_{1 L}-w \times m p c^{1}\right) T_{\alpha}+R_{1 L} T_{\mu} \mu^{\prime}(\alpha)\right]>0, \\
& \text { if and only if }\left(R_{1 L}-w \times m p c^{1}\right) T_{\alpha}+R_{1 L} T_{\mu} \mu^{\prime}(\alpha)<0 .
\end{aligned}
$$

In the model analyzed previously, we showed that strict negativity of the term $\left(R_{1 L}-w \times m p c^{1}\right)$ is both a necessary and a sufficient condition for trade to rise with an exogenous increase in terrorism in an analogous case. As is evident from equation (27), this is no longer true under the optimal counterterrorism policy because $R_{1 L} T_{\mu} \mu^{\prime}(\alpha)$ may be positive. 


\section{Bandyopadhyay and Sandler}

This difference may be clarified by the following example. Assume that $R_{1 L}<0$ such that a fall in the labor endowment raises the supply of the exportable good. Given that $T_{\mu}<0$, if counterterrorism effort rises with the terrorism-inducing $\alpha$ (i.e., $\mu^{\prime}>0$ ), ${ }^{13}$ it must follow that $R_{1 L} T_{\mu} \mu^{\prime}(\alpha)>0$. In this case, as a rise in $\alpha$ increases terrorism, the optimal counterterrorism effort must also increase. This counterterrorism response partially mitigates the exogenous rise in terrorism, thereby moderating the increase in the production of the exportable good. Consequently, the rise in export volume is also moderated compared with the case previously analyzed. As a consequence, the impact of terrorism on trade depends not only on how terrorism affects factor supplies in the export sector, but also on how counterterrorism measures may mitigate this impact. The myriad possibilities that surface go beyond the established literature that paints terrorism as necessarily having an adverse influence on trade. Our more complete analysis recognizes Samuelson's and Rybczynski's classic contributions that taught us to account for the general equilibrium nature of trade and, in particular, how factor supply affects export and import industries differently owing to factor intensity considerations.

\section{CONCLUSION}

We present three variants of a model to analyze how terrorism may affect trade through its effects on factor supplies. First, we present a two-good, two-factor model $(2 \times 2$ model $)$ and derive a necessary and sufficient condition for terrorism to raise trade. Next, we extend this model to the case of arbitrary numbers of goods and factors and derive a necessary (but not sufficient) condition for terrorism to raise trade. This general model nests the Ricardian, Heckscher-Ohlin, and the specific factors models as special cases. We show that while terrorism cannot increase trade in the single-factor Ricardian model, in the other two multifactor models it is possible for trade to rise with terrorism depending on the production structure of an economy. Finally, we present an augmented $2 \times 2$ model where counterterrorism policy is optimally chosen. The findings indicate that changes in counterterrorism policy in response to a greater terrorist threat may moderate the effect of terrorism on trade.

Our analysis should serve to dispel the notion that terrorism necessarily reduces trade for a nation affected by terrorism. The novelty of our article lies in the presentation of a competitive general equilibrium analysis of the effects of terrorism on trade flows, where factor supply effects are a central consideration. In addition, the conditions identified in this article should help in determining when terrorism should be expected to raise or reduce trade. As a general tendency, if terrorism reduces the intensive factor in the import industry, then exports and, thus, trade are generally favored. The result typically carries over to the specific factors representation when terrorism negatively affects the import industry's specific factor of production, thereby shifting resources to and increasing output of the exportable good. By reducing terrorism, counterterrorism ameliorates the impact on factor supplies-say, in the import sector-thereby reducing the increase in the export industry. Empirical measurements of exports, imports, their intensive factor supplies, and terrorism should permit a subsequent analysis of the influence of terrorism on trade. There are many possibilities, and simple rules of thumb that characterize the literature are not necessarily valid. Although some forms of 
terrorism may augment trade, this is obviously not a desirable route to enhance trade. However, knowledge of the true effect of terrorism on trade under alternative scenarios will allow for more intelligent aid and stabilization policies.

\section{MATHEMATICAL APPENDIX}

Consider the identity between Marshallian and Hicksian demand functions $D^{i}(\bullet)$ and $e_{i}(\bullet)$, respectively, at a given budget $m$, denoted as

$$
e_{i}\left[p_{1}, 1, u\left(p_{1}, 1, m\right)\right] \equiv D^{i}\left(p_{1}, 1, m\right) \Rightarrow m p c^{i}=\frac{\partial D^{i}}{\partial m}=e_{i u} u_{m} .
$$

Next, consider the identity between the expenditure function and the budget $m$ :

$$
e\left[p_{1}, 1, u\left(p_{1}, 1, m\right)\right] \equiv m \Rightarrow e_{u} u_{m}=1 \Rightarrow u_{m}=\frac{1}{e_{u}} .
$$

Using equation (A.2) in (A.1), we have

$$
m p c^{i}=\frac{e_{i u}}{e_{u}}
$$




\section{NOTES}

1 Abadie and Gardeazabal (2008); Bandyopadhyay, Sandler, and Younas (2014); Enders, Sachsida, and Sandler (2006); and Enders and Sandler (1996) provide models of terrorism and foreign direct investment that show that greater incidence of terrorism tends to reduce foreign direct investment in developing and developed nations. Bandyopadhyay and Sandler (2014), among others, indicate that terrorism may reduce productive resources available for a nation that hosts a transnational terrorist group. For more on the economic impact of terrorism, see Abadie and Gardeazabal (2003); Blomberg, Hess, and Weerapana (2004); Enders and Sandler (2012); and Keefer and Loayza (2008).

2 An interesting case is that of narco-terrorism pursued by groups such as FARC (Revolutionary Armed Forces of Colombia). Drugs are traded by such organizations to fund terrorist activities, including imports of arms for terrorists (e.g., see Library of Congress, 2002). In this scenario, terrorism directly leads to trade, albeit illegal. The mechanisms we identify in our article do not directly relate to this case; however, our model can be used as a benchmark to consider resource allocation issues relevant for such scenarios.

3 Since the effects of higher terrorism-related transaction costs have already been explored in the literature and given that their negative effect on trade is uncontroversial, we choose to focus only on the factor supply effects.

4 In a recent paper, Egger and Gassebner (2014) use a structural gravity model to investigate the effects of terrorism on trade. Their findings suggest that terrorism does not have quantitatively important effects on trade. This is not inconsistent with our findings, which suggest that both factor supply effects on production and incomeinduced changes in demand determine the ultimate effect of terrorism on trade. If, for example, terrorism reduces the production of the exportable commodity through the factor supply channel, while at the same time reducing its domestic demand through the income channel, then exports will be largely unaffected. We should note that, while Egger and Gassebner do account for a general equilibrium channel through which income may affect trade, their channel is only indirectly related to the factor supply approach highlighted here.

5 The representation below offers reduced-form models that analyze the effects of terrorism on factor supplies.

6 In a competitive economy, the partial derivative of a revenue function with respect to the price of good $i$ yields the general equilibrium supply function of good $i$. On the other hand, the partial derivative of the revenue function with respect to the endowment of factor $j$ yields the price of factor $j$. For details, see Dixit and Norman (1980).

7 Notice that the trade balance requires the value of exports to equal the value of imports at world prices. In our model, this is equivalent to $p_{1} E X^{1}=I M^{2}$, where $I M^{2}$ is the volume of import of good 2 and is the negative of net export of good 2 (i.e., $I M^{2}=-E X^{2}=e_{2}-R_{2}$ ).

8 In this derivation, we also use the fact that the expression $\left(\frac{e_{1 u}}{e_{u}}\right)$ denotes the marginal propensity to consume good 1, say $m p c^{1}$. This is established in the Mathematical Appendix.

9 Consider the reasoning behind the assumption that the capital stock remains unaffected. First, it may be that terrorism does not affect investment, although it may affect labor or land endowments. Second, in a static analysis, we can focus only on the existing stock of capital and abstract from issues of capital accumulation.

${ }^{10}$ Hardening of potential targets involves making a potential terrorist target more difficult to hit. For example, raising the security level/quality of screening at an airport considered a potential target would make it harder for terrorists to hijack planes departing from that airport. In contrast, a "soft target" is one that is undefended and easily hit by terrorists interested in doing so.

${ }^{11}$ It may seem reasonable that counterterrorism policies may not necessarily reduce terrorism, especially if there is a backlash effect (e.g., see Rosendorff and Sandler, 2010). However, in the current context, if $T_{\mu}>0$, there are no benefits from counterterrorism effort. Therefore, $T_{\mu}<0$ is a necessary condition for an interior equilibrium involving optimal counterterrorism policy.

${ }^{12}$ We assume that $T_{\mu \mu}>0$. Because $T_{\mu}<0$, the sign of $T_{\mu \mu}$ implies diminishing returns to counterterrorism effort. In addition, we assume that these diminishing returns are sufficiently strong to ensure that the second-order condition is satisfied for this optimization problem.

${ }^{13}$ Equations (23) and (24) can be used to analyze the comparative static effect of terrorism-inducer, $\alpha$, on counterterrorism, $\mu$. Among other things, a rise in $\alpha$ will tend to raise $\mu$ if $L^{\prime \prime}(T)<0$. Because $L^{\prime}(T)<0$, strict negativity of 


\section{Bandyopadhyay and Sandler}

$L^{\prime \prime}(T)$ implies increasing marginal damages resulting from terrorism. In this case, when $\alpha$ increases, it raises the level of terrorism, magnifying the marginal damage. In turn, this increases the marginal benefit of containing terrorism, thereby inducing a higher optimal level of counterterrorism effort.

\section{REFERENCES}

Abadie, Alberto and Gardeazabal, Javier. "The Economic Costs of Conflict: A Case Study of the Basque Country." American Economic Review, March 2003, 93(1), pp. 113-32.

Abadie, Alberto and Gardeazabal, Javier. "Terrorism and the World Economy." European Economic Review, January 2008, 52(1), pp. 1-27.

Bandyopadhyay, Subhayu and Sandler, Todd. "Immigration Policy and Counterterrorism." Journal of Public Economics, February 2014, 110(1), pp. 112-23.

Bandyopadhyay, Subhayu; Sandler, Todd and Younas, Javed. "Foreign Direct Investment, Aid, and Terrorism." Oxford Economic Papers, January 2014, 66(1), pp. 25-50.

Blomberg, S. Brock and Hess, Gregory D. "How Much Does Violence Tax Trade?" Review of Economics and Statistics, November 2006, 88(4), pp. 599-612.

Blomberg, S. Brock; Hess, Gregory D. and Orphanides, Athanasios. "The Macroeconomic Consequences of Terrorism." Journal of Monetary Economics, July 2004, 51(5), pp. 1007-32.

Blomberg, S. Brock; Hess, Gregory D. and Weerapana, Akila. "Economic Conditions and Terrorism." European Journal of Political Economy, Special Issue "The Economic Consequences of Terror," June 2004, 20(2), pp. 463-78.

Dixit, Avinash and Norman, Victor D. Theory of International Trade. Cambridge, UK: Cambridge University Press, 1980.

Egger, Peter and Gassebner, Martin. "International Terrorism as a Trade Impediment?" Presented at the Terrorism and Policy Conference, Center for Global Collective Action, University of Texas at Dallas, May 2014.

Enders, Walter; Sachida, Adolfo and Sandler, Todd. “The Impact of Transnational Terrorism on U.S. Foreign Direct Investment." Political Research Quarterly, December 2006, 59(4), pp. 517-31.

Enders, Walter and Sandler, Todd. "Terrorism and Foreign Direct Investment in Spain and Greece." Kyklos, August 1996, 49(3), pp. 331-52.

Enders, Walter and Sandler, Todd. The Political Economy of Terrorism. Second Edition. New York: Cambridge University Press, 2012.

Gaibulloev, Khusrav and Sandler, Todd. "Growth Consequences of Terrorism in Western Europe." Kyklos, August 2008, 61(3), pp. 411-24.

Gaibulloev, Khusrav and Sandler, Todd. "The Adverse Effect of Transnational and Domestic Terrorism on Growth in Africa." Journal of Peace Research, May 2011, 48(3), pp. 355-71.

Keefer, Philip and Loayza, Norman, eds. Terrorism, Economic Development, and Political Openness. Cambridge, NY: Cambridge University Press, 2008.

Landes, William M. "An Economic Study of U.S. Aircraft Hijacking, 1961-1976." Journal of Law and Economics, April 1978, 21(1), pp. 1-31.

Library of Congress. "A Global Overview of Narcotics-Funded Terrorist and Other Extremist Groups." Washington, DC: Library of Congress, Federal Research Division, May 2002; http://www.loc.gov/rr/frd/pdf-files/NarcsFundedTerrs_Extrems.pdf.

Nitsch, Volker and Schumacher, Dieter. "Terrorism and International Trade: An Empirical Investigation." European Journal of Political Economy, Special Issue "The Economic Consequences of Terror," June 2004, 20(2), pp. 423-33.

Rosendorff, B. Peter and Sandler, Todd. "Suicide Terrorism and the Backlash Effect." Defence and Peace Economics, October, 2010, 21(5-6), pp. 443-57.

Sandler, Todd and Siqueira, Kevin. "Global Terrorism: Deterrence versus Pre-emption." Canadian Journal of Economics, November 2006, 39(4), pp. 1370-87. 
